\title{
The Role of Visceral Hypersensitivity in Irritable Bowel Syndrome: Pharmacological Targets and Novel Treatments
}

\author{
Mohammad H Farzaei, ${ }^{1,2}$ Roodabeh Bahramsoltani, ${ }^{3}$ Mohammad Abdollahi, ${ }^{3,4 *}$ and Roja Rahimi ${ }^{5 *}$ \\ ${ }^{I}$ Pharmaceutical Sciences Research Center, Kermanshah University of Medical Sciences, Kermanshah, Iran; ${ }^{2}$ Medical Biology Research Center, \\ Kermanshah University of Medical Sciences, Kermanshah, Iran; ${ }^{3}$ Faculty of Pharmacy and Pharmaceutical Sciences Research Center, Tehran \\ University of Medical Sciences, Tehran, Iran; ${ }^{4}$ Endocrinology and Metabolism Research Center, Endocrinology and Metabolism Clinical Sciences \\ Institute, Tehran University of Medical Sciences, Tehran, Iran; and ${ }^{5}$ Department of Traditional Pharmacy, School of Traditional Medicine, Tehran \\ University of Medical Sciences, Tehran, Iran
}

Irritable bowel syndrome (IBS) is the most common disorder referred to gastroenterologists and is characterized by altered bowel habits, abdominal pain, and bloating. Visceral hypersensitivity $(\mathrm{VH})$ is a multifactorial process that may occur within the peripheral or central nervous systems and plays a principal role in the etiology of IBS symptoms. The pharmacological studies on selective drugs based on targeting specific ligands can provide novel therapies for modulation of persistent visceral hyperalgesia. The current paper reviews the cellular and molecular mechanisms underlying therapeutic targeting for providing future drugs to protect or treat visceroperception and pain sensitization in IBS patients. There are a wide range of mediators and receptors participating in visceral pain perception amongst which substances targeting afferent receptors are attractive sources of novel drugs. Novel therapeutic targets for the management of VH include compounds which alter gut-brain pathways and local neuroimmune pathways. Molecular mediators and receptors participating in pain perception and visceroperception include histamine-1 receptors, serotonin (5-hydrodytryptamine) receptors, transient receptor potential vanilloid type I, tachykinins ligands, opioid receptors, voltage-gated channels, tyrosine receptor kinase receptors, protease-activated receptors, adrenergic system ligands, cannabinoid receptors, sex hormones, and glutamate receptors which are discussed in the current review. Moreover, several plant-derived natural compounds with potential to alleviate VH in IBS have been highlighted. VH has an important role in the pathology and severity of complications in IBS. Therefore, managing VH can remarkably modulate the symptoms of IBS. More preclinical and clinical investigations are needed to provide efficacious and targeted medicines for the management of $\mathrm{VH}$.

(J Neurogastroenterol Motil 2016;22:558-574)

Key Words

Hyperalgesia; Irritable bowel syndrome; Pain perception; Pain, visceral; Visceral hypersensitivity

Received: January 8, 2016 Revised: March 26, 2016 Accepted: April 17, 2016

(.) This is an Open Access article distributed under the terms of the Creative Commons Attribution Non-Commercial License (http://creativecommons. org/licenses/by-nc/4.0) which permits unrestricted non-commercial use, distribution, and reproduction in any medium, provided the original work is properly cited.

*Correspondence: Mohammad Abdollahi and Roja Rahimi are equally responsible for this study. Mohammad Abdollahi, PharmD, PhD

Faculty of Pharmacy and Pharmaceutical Sciences Research Center, Tehran University of Medical Sciences, Tehran, Iran; Endocrinology and Metabolism Research Center, Endocrinology and Metabolism Clinical Sciences Institute, Tehran University of Medical Sciences, Tehran 1417614411, Iran

Tel: +98-2166959104, Fax: +98-2166959104, E-mail: mohammad.abdollahi@utoronto.ca Roja Rahimi, PharmD, PhD

Department of Traditional Pharmacy, School of Traditional Medicine, Tehran University of Medical Sciences, Tehran 1417653761, Iran Tel: +98-2166412653, Fax: +98-2166412653, E-mail: rojarahimi@gmail.com 


\section{Introduction}

Irritable bowel syndrome (IBS) is the most common disorder referred to gastroenterologists, which is commonly characterized by altered bowel habit, abdominal pains, bloating, and is associated with psychological disorders. ${ }^{1-4}$ It is a common gut disorder with a prevalence of 9-23\% ${ }^{5}$ which varies amongst different geographical regions and countries, with a higher prevalence in Western Europe and North America compared with other parts of the world which could be explained by a relationship between western lifestyle and gut health. ${ }^{6,7}$ Abdominal pain is a prevalent disorder within a healthy population; however, severe and recurrent pain sensation is observed frequently in IBS patients. Such painful sensation released from the gut is considered as the main cause of medical consultation in patients with IBS. ${ }^{1,2,8,9}$ While IBS is not amongst the lifethreatening diseases, the intense impact of IBS on various aspects of the patient's life leads to drawing greater global attention to this disease. ${ }^{1,2,10}$ The economic burden of IBS complications which include direct costs (diagnostic practices, consultations, and treatments) and also indirect costs (low work productivity and enhanced work absenteeism) are appraised to be between $€ 700-1600$ per patient in each year within Europe. Thus, the economic burden which has been reported to IBS managing indicates an impressive social expenditure. ${ }^{1,11}$

Several underlying mechanisms could be discussed in the pathophysiology of IBS as a multifactorial disease. Inflammatory reactions, history of childhood infections, ${ }^{12}$ hypersensitivity and alteration in visceral perception, ${ }^{13,14}$ gastrointestinal dysmotility, changes in gut microflora, emotional and psychological triggers, increase in intestinal permeability and food intolerance as well as genetic variations in bile acid secretion are amongst suggested reasons for IBS development. ${ }^{15,16}$

\section{Conventional Treatment of Irritable Bowel Syndrome}

Due to the wide range of IBS clinical manifestations, several treatment strategies are used to control the disease symptoms. ${ }^{17,18}$ Classic pharmacotherapy of IBS includes management of diarrhea/ constipation, abdominal pain, and bloating. In diarrhea-predominant IBS (IBS-D), antidiarrheal agents like loperamide are used to control the symptoms; though, recent studies are considering other types of drugs like mesalazine in the management of diarrhea. ${ }^{19} \mathrm{On}$ the other hand, constipation could be controlled with polyethylene glycol and lactulose as well as bulking agents (Psyllium and bran), milk of magnesia and stimulant laxatives (senna and bisacodyl). ${ }^{20}$ Other agents include anticholinergics and antispasmodics for abdominal pain and carminatives for flatulence. ${ }^{21}$ In addition, new drug categories are being investigated for IBS management, which, at least in part, focus on the psychological aspects of the disease pathophysiology. Several antidepressants, including imipramine, clomipramine and nortriptyline from tricyclic antidepressants as well as citalopram and fluoxetine from selective serotonin reuptake inhibitors were tested in human subjects to control IBS symptoms; nevertheless, more clinical evidences are needed to confirm the effects of antidepressants. ${ }^{22,23}$

\section{Visceral Hypersensitivity}

Functions of visceral organs, such as gastrointestinal distensions and contractions, in non-pathological conditions has normally no pain. Altered sensation in response to physiological stimuli is defined as visceral hypersensitivity (VH). Pressure or volume augmentations applied to the bowel induced mechanical stimuli. In clinical manifestation, $\mathrm{VH}$ is defined as an enhanced perception of mechanical triggers applied to the bowel which seems as pain and discomfort. ${ }^{24,25} \mathrm{VH}$ is a disorder of biopsychosocial diseases as in functional dyspepsia or IBS. Two major components of $\mathrm{VH}$ are allodynia and hyperalgesia. Hyperalgesia is defined as an intensified pain sensation in response to stimuli which usually provoke pain, whereas allodynia refers to the elevated nociceptive sensation in response to normal stimuli. Previous studies exhibited that $\mathrm{VH}$ is generated from disturbance in the peripheral sensory pathway and/or central nervous system (CNS). In fact, VH is known as decreased thresholds of stimuli perception generated from the gastrointestinal tract. ${ }^{24-26}$ Epidemiological surveys have demonstrated different estimation of prevalence of $\mathrm{VH}$ in patients with IBS which varied from $33 \%$ to $90 \% .^{27-29} \mathrm{VH}$ generally occurs in IBS-D patients, who have increased intestinal permeability. ${ }^{13,30}$ Clinical studies demonstrated that the severity of IBS complications in patients with hypersensitivity IBS is dramatically higher than other IBS patients. Although primary investigations have restricted the occurrence of $\mathrm{VH}$ to the rectum and sigmoid colon, numerous studies reported that decreased thresholds of nociceptive sensation were observed within other parts of the gut including the small bowel, stomach, as well as the esophagus, indicating the spread of $\mathrm{VH}$ within all over the gut. ${ }^{26,28,31,32}$ 


\section{Pathophysiology and Etiology of Visceral Hypersensitivity}

For the first time in 1973, it was observed that pain responses to rectal balloon distensions in patients with IBS are remarkably higher than healthy subjects. Afterwards, a large body of clinical studies has reported that pain perception as well as discomfort in response to rectal distension are intensified in IBS patients, which indicates the contribution of VH in IBS symptoms. ${ }^{26,33,34}$ The exact pathogenesis of the $\mathrm{VH}$ and association of altered visceroperception in clinical symptoms of IBS has not been unveiled; though, recent pathophysiological investigations have recognized a wide range of features which result in gastrointestinal dysmotility and visceral sensitivity via initiating complex cascades. In fact, $\mathrm{VH}$ condition is a multifactorial process that may occur both within the peripheral nervous system and at the level of CNS function. Several factors, including microbial infections, intestinal microbiota, psychological factors, inflammation and immunological factors, brain-gut communication, diet, as well as genes, are involved in the manifestation of gastrointestinal symptoms of IBS particularly $\mathrm{VH}^{33,35-37}$ Given the fact that IBS can be induced via an acute episode of infective gastroenteritis indicates the significant role of peripheral factors involving pain perception in IBS. ${ }^{35,36}$ Likewise, it is suggested that psychosocial factors possess a pivotal role in bowel motility and visceral sensation. Patients with IBS showed a higher incidence of depression (20-30\%) or anxiety (15-45\%) in comparison to healthy individuals. It has been confirmed that these factors are involved in the severity of IBS symptoms and visceral pain via affecting braingut interaction, central pain perception, and intestinal motor function. ${ }^{38}$ In addition, intestinal permeability is among the key factors associated with the severity of IBS complications and visceral sensitization. $^{33}$

Disturbance in the immune system of the gastrointestinal tract, neural pathways, gut endocrine characteristics as well as microbiological condition of the gut alters nociceptive transmission from the periphery to the brain via sensory nerve signaling in large subsets of subjects with IBS. ${ }^{39}$ Commensal intestinal bacteria as well as gut pathogens can obviously alter visceral nociception mediated by regulating visceral afferents directly or through a disturbing gut barrier function and intestinal immune system. ${ }^{40,41}$ Accumulating evidence suggests that disturbance in the enteric neuroendocrine system is an important contributor in altered intestinal perception. ${ }^{42}$

Clinical investigations have reported that microRNA expression increases in the colonic tissue of IBS patients. It has been found that these microRNAs can promote epigenetic and genetic events through modulating intestinal pathways, such as $5-\mathrm{HT}$ signaling which result in intestinal permeability and somatic hypersensitivity in IBS patients. ${ }^{43}$ Intestinal tissue inflammation possesses the potential to alter gut wall function, increasing the release of inflammatory mediators which lead to stimulation of sensory afferent nerve endings within the gastrointestinal tract. Inflammation is able to cause post-inflammatory hyperalgesia and is among the principal local factors involved in VH occurring in patients with IBS. ${ }^{44}$ Distal peripheral afferents including mucosal afferents, serosal and mesenteric afferents, as well as muscular afferents have a principal role in gut-brain axis communication. It has been confirmed that one of the main mechanisms involved in the pathophysiology of $\mathrm{VH}$ in IBS symptoms is sensitization of the distal peripheral afferents. In response to a transient inflammation, amongst distal peripheral afferents, the mesenteric and serosal afferents within the splanchnic pathway regulate prolonged visceral sensitization. Likewise, these afferents also possess chemosensitivity to a wide range of agents such as ATP and bradykinin, which result in induction of post-inflammatory VH. Besides, mechanically insensitive afferents within the colorectal pelvic and lumbar splanchnic pathways possess the potential to acquire mechanosensitivity causing neural activation in pathological inflammatory conditions. ${ }^{45}$

\section{Pharmacological Aspects of Visceral Hypersensitivity and Irritable Bowel Syndrome}

Novel therapeutic agents for the management of $\mathrm{VH}$ include compounds which alter gut-brain pathways and local neuroimmune pathways. Since gastrointestinal hyperalgesia is commonly associated with muscular spasms, molecules attenuating contractions of gut smooth muscles can improve $\mathrm{VH}$. In addition, therapeutic agents which are able to suppress neural activation and signaling from the gastrointestinal tract to the CNS possess a principal role in controlling $\mathrm{VH}$. Below are the main molecular targets corresponding with improving VH in IBS. ${ }^{4,39}$

\section{Immunological and Inflammatory Pathways}

Several inflammatory mediators, including neuropeptides, cytokines, and prostanoids have a pivotal role in the peripheral sensitization of mucosal neuronal afferents and VH. It has been reported that elevated amount of mast cells is associated with visceral hyperalgesia. Clinical trials on IBS patients revealed that the amount of activated mast cells within the proximity of bowel enteric 
nerves is associated with the incidence and severity of enhanced visceroperception. ${ }^{46-48}$ Animal models of post-infectious gut dysfunction exhibited that inflammatory pathways obviously affect sensory motor performance. Clinical evaluation showed that gastrointestinal levels of prostaglandin E2 as well as immune cells, including $\mathrm{CD} 25+\mathrm{T}$ cells were elevated in the intestinal mucosa of patients with IBS. Likewise, mRNA expression of the pro-inflammatory mediator, IL-1 $\beta$, has been reported in patients with post-infectious IBS. It has been suggested that the pro-inflammatory cytokines affect the performance of enteric nerves as well as sensory innervations with the motivation of irregular secretomotor responses within the gastrointestinal tract, causing altered pain threshold and visceral sensory perception which resulted in the generation of gut pain and discomfort. ${ }^{46-48}$ Human studies demonstrated that 5-aminosalicylic acid, an anti-inflammatory drug in the gut, significantly alleviates pain perception mediated by reducing intestinal immune cells. ${ }^{19,49,50}$

Toll-like receptors (TLRs) have a crucial role in encoding specific receptors involved in abnormal visceral perception. Within the pathogenesis of post-infectious IBS, TLRs, particularly TLR9, modulate host immune reactions to enteric bacteria and encode defense proteins in the epithelial barrier. Moreover, TLRs is involved in the motivation of neuroimmune responses which is activated by psychological stress in patients with $\mathrm{VH}^{51,52}$ Intravenous, intracerebroventricular, and also the intraprefrontal cortex administration of TAK-242, which is a specific antagonist of TLR4, remarkably suppressed $\mathrm{VH}$ induced by chronic stress. ${ }^{53}$

\section{Histamine-1 Receptor}

According to clinical investigations, histamine-1 receptors are significantly elevated in intestinal and colonic mucosa of IBS patients in comparison to healthy subjects. Mucosal release of histamine and tryptase, mediators of mast cell is considered as one the contributors in the activation of visceral nociceptive sensory pathways. ${ }^{54-56}$ It is assumed that antagonists of histamine-1 receptors, which are biologically restricted to peripheral organs, have the ability to manage hypersensitivity and motility. An animal study on altered visceral perception revealed that second generation antagonists of histamine-1 receptors, including ebastine and fexofenadine can remarkably alleviate stress associated $\mathrm{VH}^{54}$ Ketotifen, which is an antagonist of histamine-1 receptor and a mast cell stabilizer, can significantly reverse hyperalgesia and relieve discomfort and abdominal pain, as well as clinical digestive symptoms in IBS patients with $\mathrm{VH}^{56}$

\section{Serotonin}

Serotonin (5-hydrodytryptamine; 5-HT) is an important neurotransmitter and paracrine signaling substance which mediates mutual communication between the brain and the gut. In the human body, this molecule is mainly (90-95\%) produced by the enterochromaffin cells of the intestinal mucosa as well as by subgroups of enteric neurons. 5-HT is the responsible agent for bloating, nausea, vomiting, and chemotherapy associated pain. ${ }^{57,58}$ A large body of evidence confirmed that mucosal stimulation causes 5-HT release, which results in induction of the peristaltic reflex. Targeting 5-HT receptors as well as 5-HT uptake mechanisms possess a key role in the production of effective treatment in $\mathrm{VH}$ associated disorders. ${ }^{58,59}$ A clinical study of patients with IBS suffering from $\mathrm{VH}$ exhibited that alosetron, a $5-\mathrm{HT}_{3}$ receptor antagonist, can significantly improve gastrointestinal symptoms, including higher volume thresholds and reducing colonic compliance. ${ }^{60}$ Subsequent to aversive rectal exciting, alosetron obviously reduces the emotional motor system of brain activity leading to modulation of the gut sensitivity. ${ }^{61}$ In addition, tegaserod which is a partial agonist of $5-\mathrm{HT}_{4}$ receptor significantly reduced sensitivity to rectal distension and improved visceral sensation in both patients and healthy subjects. ${ }^{62-64}$

The $5-\mathrm{HT}_{7}$ receptor which participates in nociceptor activation and its chemical antagonists have a strong rationale for drug development to manage functional gut disorders, particularly visceral sensitivity. 5- $\mathrm{HT}_{7}$ receptors are expressed in afferent nociceptors terminating in the superficial layers of the spinal cord. Inhibiting $5-\mathrm{HT}_{7}$ receptors causes the elevation of pressure threshold which results in blockage of stimulating intestinal peristalsis and reduction of bowel compliance. Nevertheless, our knowledge about this 5-HT subgroup is restricted and the perfect mechanism of this receptor in brain-gut axis must be found. ${ }^{57,65}$

\section{Transient Receptor Potential Vanilloid Type I}

Transient receptor potential vanilloid type I (TRPV1) is a significant contributor in colorectal mechanosensation as well as inflammation-induced pain. TRPV1 is a member of the family of TRP receptors expressed within the nervous system of the brain, especially on small-to-medium sized neurons, and there is a strong motivation on TRPV1 for drug discovery in relation to $\mathrm{VH}^{66,67}$

In response to intestinal inflammatory conditions, locally produced nerve growth factor (NGF) modulates the expression of TRPV1 and enhances the sensitivity of the receptor. In fact, NGFmediated p38 kinase pathway is involved in enhancing the expression of TRPV1 which is mediated by the inflammatory cytokines, 
PGs and bradykinin. Activation of TRPV1 is related to protein kinase $\mathrm{C}$ as well as cAMP-dependent protein kinase which cause phosphorylation of the receptor, resulting in facilitation of colorectal afferent neuron sensitization. In contrast, protein phosphatases mediate dephosphorylation of TRPV1 leading to its desensitization. Experimental studies have showed that TRPV1 is activated by capsaicin and its analogues, as well as other substances like resiniferatoxin. Clinical investigations revealed that the levels of TRPV1 are elevated in patients with rectal hypersensitivity and that there is a significant association between the enhancement of TRPV1 and sensory response to rectal distension. ${ }^{68,69}$ Likewise, TRPV1 has a principal role in the induction and maintenance of persistent colonic sensitivity, which is induced by neonatal colon irritation in rats. There is considerable interest in targeting TRPV1 receptors and neuronal growth factors in order to discover novel therapies for alleviating visceral pain. Intraperitoneal injection of TRPV1 antagonists significantly reduced sensitivity of the colon to balloon distention in adult rats compared with control animals. ${ }^{70}$ SB366791, a TRPV1 antagonist, noticeably inhibited CCL2- induced thermal hyperalgesia mediated by suppressing nociceptive signaling and synaptic transmission. ${ }^{71}$ TRPV1 antagonists like capsazepine modulate inflammatory associated visceral pain and disease severity in dextran sodium sulfate-induced IBD. . $^{67,2}$

\section{Tachykinins}

Tachykinins are specific peptides including neurokinin (NK) $\mathrm{A}$ and $\mathrm{B}$, and also substance $\mathrm{P}$ which are expressed within the small diameter sensory fibers of the gut. These peptides affect NK1, NK2, as well as NK3 receptors, which are expressed within the $\mathrm{CNS}$ as well as the autonomic nervous system. Current experimental studies have demonstrated the significant role of $\mathrm{NK}$ receptors in VH. It has been reported that NK receptors as well as substance $\mathrm{P}$ affect sensory neurons and are involved in nociceptive sensation. In vivo studies showed that SR-140333 and MEN-10930, 2 selective antagonists of NK1 receptors, possess significant alleviating effects on inflammatory associated hyperalgesia. ${ }^{73-75}$ Different animal studies have confirmed that nepadutant and saredutant, 2 NK2 antagonists, can significantly modulate the colorectal hypersensitivity to distension. Talnetant, SB-223412, and SR-142801 are amongst the selective antagonists of NK3 receptors. Peripheral administration of SR-142801 suppresses inflammatory associated $\mathrm{VH}^{74-77}$

\section{Opioid Receptors}

Opioid receptors, including $\delta, \mu$, and $\kappa$ receptors are expressed within submucosal and myenteric plexus of the gut, and also vis- ceral nociceptive sensory pathways. A large body of investigations reported that opioid receptors play an important role in modulating gut secretion and motility, as well as colorectal perception. Experimental studies exhibited that fedotozine and asimadoline are among agonists of $\kappa$-opioid receptors which can significantly reduce pain sensation. ${ }^{78,79}$ In a clinical trial on patients with IBS, fedotozine significantly decreased volume or pressure stimuli perception. Likewise, in another clinical study, asimadoline alleviated functional dyspepsia symptoms, particularly hyperalgesia. ${ }^{79,80}$ It has been found that activation of $\mu$-opioid receptors by exogenous opioids can reduce bowel transition. Eluxadoline, a $\mu$-opioid receptor agonist and $\delta$-opioid receptor antagonist, showed a significant elevation in pain threshold in IBS-D patients. ${ }^{80,81}$

\section{Tyrosine Receptor Kinase Receptors}

Tyrosine receptor kinase (Trk) receptors, a group of tyrosine kinases, possess modulatory activity on synaptic plasticity as well as adjustment of neuronal transmission strength within the nervous system. It has been found that the level of the Trk high affinity receptor (TrkA) expressing fibers is significantly elevated in patients with rectal hypersensitivity and fecal urgency. It has been recognized that amongst Trk receptors (A, B, and C), TrkA is mainly expressed in nociceptive sensory neurons. Neurotrophins, particularly NGF, are amongst the main molecules that act on Trk receptors and TrkA possess the highest affinity to this substance. ${ }^{82,83} \mathrm{k} 252 \mathrm{~A}$, a TrkA antagonist, significantly attenuated $\mathrm{VH}$ to colorectal distension induced by chronic stress-induced in mice. ${ }^{84}$ Visceral inflammation stimulates $\operatorname{TrkB}$ which is commonly expressed in visceral afferents through brain-derived neurotrophic factors and results in regulating painful sensation. Preclinical examinations confirmed that systemic NGF induces hyperalgesia mediated by activation of peripheral terminals in nociceptive neurons. ${ }^{82,83,85}$

\section{Voltage-gated Channels}

Voltage-gated channels are stimulated by tissue-damaging motivations, which cause alterations in pain thresholds mediated by increase in sensitivity of peripheral neurons. Voltage-gated potassium channels have a principal role in regulating neuronal activation; thus, peripheral hypersensitivity can be obviously modulated via blocking potassium currents. The 2 major types of voltage-gated potassium channels are the sustained delayed rectifier current and the transient A-type current. ${ }^{86,87}$ The increased level of potassium can lead to depolarization of the cell membrane in smooth muscles, which is associated with the entry of extracellular calcium ions as well as stimulation of bowel contractions. It has been suggested 
that ryanodine and inositol triphosphate receptors are involved in depolarization-induced calcium currents in muscle cells. ${ }^{87}$

In electrically motivated cells, voltage-gated calcium channels provide the main current of $\mathrm{Ca}^{2+}$ from extracellular tissue to the cytosol. Voltage-gated calcium channels consist of pore forming $\alpha_{1}$ subunits as well as different smaller subunits such as $\beta, \gamma, \alpha_{2}$, and $\delta$. Marger et $\mathrm{al}^{88}$ reported that elevation of the current density in the $\mathrm{T}$ type calcium channel (a subfamily of voltage-gated calcium channels) within colonic nociceptors can exacerbate VH. Calcium channel antagonists, mibefradil, ethosuximide, and NP078585 can remarkably inhibit butyrate-induced $\mathrm{VH}$ in rats.

Voltage-gated sodium channels produce the rising phase of the action potential mediated by enhancing sodium ion permeability in the neuronal cell membrane. They can also reduce the activation threshold and enhance current density. Voltage-gated sodium channels, in addition to voltage-gated $\mathrm{K}$ channels, regulate the excitability of sensory neurons. Clinical evidence has confirmed the contribution of sodium channels in visceral sensation. In a doubleblind crossover clinical trial, the intra-rectal injection of lidocaine, a blocker of voltage gated $\mathrm{Na}$ channels, increased pain threshold and mitigated rectal hypersensitivity in patients with IBS. ${ }^{89}$ In an in vivo study on A-803467, a selective Nav1.8 sodium channel blocker, showed that this molecule can attenuate mechanical allodynia and thermal hyperalgesia in visceral tissues. ${ }^{90}$ Such therapeutic effects was also observed with administration of ambroxol, another $\mathrm{Na}^{+}$ channel blocker, in animal models of inflammatory pain in rats. ${ }^{91}$

\section{Adrenergic Receptors}

The receptors involved in the norepinephrine pathway belong to a subfamily of $\mathrm{G}$ protein-coupled receptors, which contain $\alpha$ and $\beta$ subtypes. Chronic stress can cause overexpression of brain $G$ proteins along with colonic adrenergic $\alpha_{2 A}$ receptors, which are able to induce visceral perception in IBS patients. Likewise, the norepinephrine reuptake transporter has a principal contributor in stress associated visceral perception. ${ }^{92}$ Winston et $\mathrm{al}^{93}$ reported that inhibition of adrenergic $\alpha 1 / \alpha 2$ as well as $\beta 1 / \beta 2$ receptors significantly protects against heterotypic chronic stress-induced $\mathrm{VH}$ in rats. Within the distal colonic epithelium, $\beta 1$ and $\beta 2$ adrenergic receptors are implicated in the stimulation of electrogenic $\mathrm{K}^{+}$currents with significant roles in colonic perception. $\beta 2$ adrenergic receptors are expressed on primary afferent nociceptors and modulate pain perception in the animal gut. Systemic propranolol, an antagonist of $\beta$-adrenergic receptor, can significantly mitigate heterotypical, intermittent, and stress-induced $\mathrm{VH}$ in rats; however, an antagonist of the $\alpha$-adrenergic receptor, phentolamine, did not affect viscero- motor responses to colorectal distension. Administration of specific antagonists of $\beta$-adrenergic receptors showed that among $\beta 1, \beta 2$ and $\beta 3$ receptors, only $\beta 2$ antagonists obviously suppressed visceral sensitivity induced by heterotypical intermittent stress in animals. In fact, increased secretion of norepinephrine in serum can remarkably trigger $\beta 2$ adrenergic receptors, which cause reduction of sensation threshold in colon-specific dorsal root ganglia. ${ }^{92,93}$

\section{Glutamate Receptors}

The main excitatory neurotransmitter within the CNS is glutamate. N-methyl-D-aspartate (NMDA) and $\alpha$-amino-3-hydroxy5-methyl-4-isoxazolepropionic acid (AMPA) are the binding receptors of glutamate. In experimental models of $\mathrm{VH}$, the function of the glutamate NMDA receptor is obviously enhanced within the anterior cingulate cortex. ${ }^{94}$ Likewise, persistent stimulation of the AMPA receptor, which has a key role in regulating rapid excitatory transmission as well as synaptic plasticity, is involved in hyperalgesia. ${ }^{95}$ AMPA receptor consists of four subunits, which include GluR1, GluR2, GluR3, and GluR4, which form tetramer structures. The GluR2 subunit participates in the development of $\mathrm{VH}$ which is induced via intracolonic administration of mustard oil. ${ }^{94}$ The non-selective antagonist of glutamate AMPA receptor, named 6-cyano-7-nitroquinoxaline-2,3-dione disodium salt, remarkably alleviated visceral perception induced by substance $\mathrm{P}^{96}$

\section{Sex Hormones}

Sex hormones are significant contributor in the stimulation of the $\mathrm{VH}$ process in animal models. Estrogen participates in the development of the stress associated $\mathrm{VH}$ in female rats. One of the experimental methods for induction of stress-induced $\mathrm{VH}$ is neonatal maternal separation, which potentially results in the perception of pain in response to colorectal distension in rats. ${ }^{97}$ Likewise, it has been shown that estrogen is involved in colonic perception, which is stimulated by peripheral chemical sensitization. Estrogen contributes to the central sensitization of visceral pain through spinal activation of cAMP-response element binding protein pathways which modulate transcriptional signaling within the dorsal root ganglion as well as the CNS. In contrast, loss of gonadal hormones in ovariectomized rats significantly blocked the pathological process of $\mathrm{VH}$, which is reversed by administration of exogenous estrogen. ${ }^{98,99}$

\section{Cannabinoid Receptors}

Accumulating evidence has suggested that the endocannabinoid pathway has a principal role in several neuronal processes. There are 2 major types of cannabinoid receptors, $\mathrm{CB} 1$ and $\mathrm{CB} 2$ 
receptors. CB1 receptors are associated with the adverse effect of cannabinoids, including catalepsy and hypothermia, and CB2 receptors, which are mainly located in the myenteric and submucosal plexus of the gastrointestinal tract, are associated with mitigating gut motility and pain perception. ${ }^{100}$ RQ-00202730, a selective agonist of the $\mathrm{CB} 2$ receptor, can remarkably alleviate visceral hyperalgesia stimulated by trinitrobenzenesulfonic acid (TNBS) in an animal model of IBS. The selective CB2 receptor agonist which has no adverse effect of cannabinoid pathway associated with CB1 receptor, can be considered as a safe and efficacious future drug for managing VH. Likewise, such a therapeutic effect has been reported by another selective CB2 receptor, PF-03550096, in animal models of VH induced by TNBS. ${ }^{100,101}$

\section{Protease-activated Receptors}

Proteases participate in nociception signaling through affecting several groups of ligands like protease-activated receptors (PAR). PAR is a member of the family of seven transmembrane domains, namely G-protein-coupled ligands, which is stimulated via proteolytic cleavage of their extracellular $\mathrm{N}$-terminal domain and the ensuing binding of the newly released $\mathrm{N}$-terminus. There are four main PAR receptors, which include PAR1, PAR2, PAR3, and PAR4. These receptors are directly or indirectly able to act on conducting and/or blocking pain sensation mediated by sensory neurons. ${ }^{102,103}$ In fact, PAR2 seems to be a pro-nociceptive receptor which participates in nociception and sensitization; though, PAR4 and PAR1 possess the potential to block nociceptive sensation. ${ }^{103,104}$ In addition, PAR4-deficient animals revealed more intensive visceral sensation induced by mustard oil (intracolonic administration) in comparison to wild-type mice. ${ }^{102,104}$ Administration of AYPGKF$\mathrm{NH}(2)$, a PAR4 agonist peptide, noticeably alleviated the visceromotor response to colorectal distension in mice. Intracolonic administration of PAR4 agonists significantly mitigated hyperalgesia and allodynia in response to colorectal distension induced by PAR2 agonists. In fact, agonists of PAR4 modulate VH by suppression of free intracellular calcium mobilization which is stimulated by the pro-nociceptive PAR2 agonists. ${ }^{102,103}$

Subjects with post-infectious IBS showed an elevation in proteolytic activity in the colonic tissue. In patients with IBS, tryptase (which is released from mast cells), as well as serine proteases of bacteria (eg, gingipains-R) has a key contributor in the neuronal signaling of hypersensitivity via PAR2 stimulation. Some serineproteases like thrombin are able to stimulate PAR1 but not PAR2, indicating their potential for mitigating nociceptive sensation. ${ }^{104,105}$ Antagonizing PAR2 receptors as well as activation of PAR1 and
PAR4 receptors by selective agonists can be considered as novel therapeutic targets for managing VH in IBS patients. ${ }^{105}$

\section{Gut Microflora}

Initially after birth, the human baby becomes infected with a huge number of microorganisms which start to form the normal flora of the body. ${ }^{106,107}$ The main part of the body containing the microorganism is the intestine with a population of about one thousand $\mathrm{CFU} / \mathrm{mL}$ of microbes which is hundreds of times higher than the human cells. ${ }^{108}$

The importance of gut microbiota is because of its activity to metabolize non-digestible large polysaccharide fibers, vitamin $\mathrm{K}$ synthesis, bowel cells growth, and immune system modulation as well as prevention of pathogen colonization. ${ }^{106}$ Once an alteration in the composition of gut microflora occurs, the result would be gastrointestinal complications, including changes in bowel habits, abdominal pain and bloating, which are common symptoms amongst IBS patients as well. In such situations, one of the safest therapeutic approaches (along with antibiotic or other therapies, if necessary) is to use probiotics.

Probiotics are special types of generally recognized as safe bacteria and yeasts with beneficial effects for human health and are famous for their positive role in the relief of signs and symptoms of several functional gut disorders including IBS. ${ }^{109}$ Lactobacillus and Bifidobacterium species as well as Bacillus coagulans from bacteria and Saccharomyces boulardii as a yeast probiotic are the most wellknown strains in the management of gastrointestinal disorders. ${ }^{110-112}$

In vitro and animal studies revealed that multispecies probiotic preparations exert beneficial effects via prevention of hyperpermeability, decrease in occludin (a protein with a crucial role in regulation of tight junctions) degradation by inflammatory phase enzymes, elevation of Zona occludens protein-1 (ZO-1) (which acts as cross-linkers in tight junctions) expression, and reduction in VH. ${ }^{113}$ Oral administration of Bifidobacterium and Lactobacillus as well as their mixture remarkably reduced intestinal permeability as well as the contractile response of colonic smooth muscles in mice with IBS. ${ }^{41}$ The probiotics significantly alleviated VH symptoms of post-infectious IBS in animals which is mediated by suppression of intestinal inflammation and release of inflammatory cytokines. Early life administration of a mixture of 8 probiotic bacteria strains prevented the development of $\mathrm{VH}$ induced by neonatal maternal separation in rats via regulation of pain mediator transmission as well as inflammatory cytokines. ${ }^{114}$

A randomized, double-blind, placebo-controlled clinical trial on moderate to severe IBS patients showed that a liquid non-dairy 
probiotic product containing Lactobacillus rhamnosus, Lactobacillus plantarum, Lactobacillus acidophilus, and Enterococcus faecium could enhance patient satisfaction due to decrease in abdominal pain. ${ }^{115}$ On the contrary, in a randomized, double-blind, placebocontrolled setting, Roberts et $\mathrm{al}^{116}$ could not find a significant change in overall outcomes of constipation-predominant IBS and mixed stool form-IBS patients using a multispecies probiotic mixture. In a systematic review of Moayyedi et $\mathrm{al}^{117}{ }^{11}$ it is mentioned that in animal studies it was proposed a positive role for probiotics to reduce $\mathrm{VH}$; though there are still controversial data on the potential of probiotics which requires high quality clinical trials to provide enough evidence.

\section{Plant-derived Natural Compounds as Novel Drugs for Visceral Hypersensitivity}

\section{Curcumin}

Curcumin is a second metabolite from turmeric, which has long been used as a spice because of its pleasant color and odor. Curcumin has a wide range of therapeutic properties including antioxidant, ${ }^{118}$ anti-inflammatory, ${ }^{119}$ antimicrobial, ${ }^{120}$ antidepressant, ${ }^{121}$ immunomodulatory $^{122}$ and antinociceptive ${ }^{123}$ effects. Previously, a pilot study on turmeric extract suggested the beneficial effects of this medicinal plant in IBS patients. ${ }^{124}$ In an animal study, curcumin alleviated anxiety and depressive like behaviors in rats with IBS. Brain derived neurotrophic factor, 5-HT, and phosphorylation of cAMP-response element binding proteins were also modulated both in the peripheral nervous system and the CNS. The 5-HT1A receptor is suggested to be involved in the curcumin mechanism of action for the management of $\mathrm{VH}$ in rats with IBS. ${ }^{125}$ Another in vivo study showed a remarkable decrease by curcumin in visceromotor response to colorectal distension in rats. ${ }^{126}$ Ex vivo assessments on TNBS- treated jejunum confirmed the peripheral effect of curcumin on mesenteric afferent nerves. It was also demonstrated that curcumin, at least in part, interacts with TRPV $1 .{ }^{126,127}$

\section{Dicentrine}

Dicentrine is a plant derived alkaloid with $\alpha$ adrenoceptor antagonist and anti-platelet activity. ${ }^{128,129}$ Oral administration of dicentrine in complete Freund's adjuvant model of cutaneous inflammation demonstrated the antinociceptive effect in mechanical and cold hypersensitivity, as well as chronic inflammatory pain. Dicentrine reversed the pain caused by intraplantar injection of cinnamaldehyde, which is an activator of transient receptor potential cation channel 1 receptors which are involved in visceral pain caused by inflammatory conditions and stimuli. ${ }^{130}$ In addition, in the acetic acid-induced abdominal pain animal model, dicentrine could decrease visceral pain perception. ${ }^{131}$

\section{Berberine}

Berberine is an alkaloid found in several plants amongst which the most famous ones are Berberis spp. from the family Berberidaceae. ${ }^{132,133}$ Anti-inflammatory, ${ }^{134}$ antioxidant, ${ }^{135}$ and anti-ulcer ${ }^{136}$ activity of berberine chloride have been demonstrated in several studies. Deng et $\mathrm{al}^{137}$ evaluated 12 berberine derivatives, which showed their remarkable activity for the treatment of IBS. In a post inflammation-IBS model induced by $4 \%$ acetic acid in rats, abdominal withdrawal reflex scores to colorectal distention were significantly lower in berberine treated animals compared with a placebo group, which represents the activity of berberine in reduction of VH. Berberine could also decrease defecation times and improved stool consistency. Inhibition of berberine effect by the concomitant administration of aminoguanidine (a nitric oxide synthetase inhibitor) suggests a role for nitric oxide in the visceral antinociceptive effect of berberine. ${ }^{138}$ Berberine could be proposed as an adjuvant treatment for IBS; however, recent studies showed an alteration in plasma level of berberine in animal models of IBS which suggests the necessity of dose adjustment for patient with IBS. ${ }^{139}$

\section{Ginseng Saponins}

Ginseng is an ancient medicinal herb native to China and eastern Asia with several health promoting effects. ${ }^{140}$ Ginsenosides, the active ingredients of ginseng belonging to the saponins class of phytochemicals, have an inhibitory activity of the $5-\mathrm{HT}_{3 \mathrm{~A}}$ receptor. Total ginseng saponins were evaluated for their healing activity in a rat model of IBS which resulted in significant differences with negative control. In addition, 2 subtypes of ginseng saponins, protopanaxadiol ginsenosides and protopanaxatriol ginsenosides, showed that protopanaxatriols are more effective than protopanaxadiols. ${ }^{141}$ Total ginseng saponins showed antinociceptive activity in animal models of $\mathrm{VH}$, which was performed by assessing the number of contractions in the external oblique muscles of rats during the colorectal distention period. $^{142}$

\section{Tetrahydropalmatine}

Tetrahydropalmatine is an isoquinoline alkaloid mainly found in Stephania and Corydalis species. ${ }^{143}$ Pharmacological activities like beneficial effects in myocardial ischemia-reperfusion injury have been reported from this compound. ${ }^{144} \mathrm{JCM}-16021$ is a multi com- 
ponent herbal medicine composed of seven plants amongst which one is standardized based on tetrahydropalmatine amount. Antinociceptive effects of JCM-16021 were assessed in a neonatal-maternal separation model of visceral pain. Pain threshold in response to colorectal distention was significantly increased in the JCM-16021 treated group. ${ }^{145}$ Intragastric administration of tetrahydropalmatine noticeably suppressed primary hyperalgesia in response to both thermal and mechanical stimuli in rats. This molecule also significantly alleviated mirror-image thermal hyperalgesia induced by bee venom in comparison to the control group. Pre-administration of tetrahydropalmatine in the acetic acid-induced visceral pain group resulted in significant antinociceptive effect in comparison to the negative control group. Tetrahydropalmatine demonstrated modulatory effect on mechanical and thermal inflammatory pain hypersensitivity along with suppression of visceral nociception which is mediated by the supraspinal level of nociceptive signaling. ${ }^{143}$

\section{Complementary and Alternative Therapies for the Management of Visceral Hypersensitivity in Irritable Bowel Syndrome}

Due to the chronic undesirable complications of IBS which overshadows the quality of life, a growing number of patients are seeking complementary and alternative medicine (CAM) to manage their symptoms. It is reported that around half of IBS patients are using CAM along with their conventional medicaments. ${ }^{146,147}$ Traditional herbal formulas, acupuncture, meditation, hypnotherapy, as well as manipulative and body-based practices are amongst different types of CAM being used by IBS patients. ${ }^{148}$ Some of these methods like acupuncture-moxibustion and hypnotherapy showed beneficial effects on the relief of IBS symptoms and alleviation of visceroperception mediated by regulating brain-gut axis peptides, as well as mediators of the neuroendocrine system. ${ }^{149,150}$ Several clinical trials on different subgroups of patients with IBS confirmed the efficacy of acupuncture-moxibustion in managing gut complications, including improving low threshold of the rectal sensation, gut motility, and pain perception, indicating their therapeutic benefits on VH. ${ }^{149,151-153}$ Nevertheless, there is still a need for clinical trials to be set up for providing evidence on the dose, duration, and efficacy of different types of CAM. ${ }^{147}$

\section{Discussion}

IBS is considered as the most common disorder referred to gastroenterologists. Several conventional drugs have been used for
IBS which are not satisfactory in managing symptoms and achieving remission and possess numerous side effects. IBS has a multifactorial pathophysiology in which VH, disturbance in gut motility, inflammation and immune disturbance, as well as psychological factors are among the key contributors. A large body of evidence has suggested that IBS is considered as a heterogeneous disorder with VH as a pivotal biological hallmark. ${ }^{10,23,33}$

VH means decreased thresholds of stimuli perception generated from the gastrointestinal tract, which plays as a key pathophysiological mechanism in nociceptive sensation in large subgroups of patients with functional gastrointestinal disorders, particularly IBS. $^{33,39}$ The exact etiology of VH has not been recognized; however, it is hypothesized that both peripheral and central neural mechanisms are involved in the pain sensitization. ${ }^{154}$ Given the fact that $\mathrm{VH}$ is considered as a paramount clinical manifestation observed in patients with IBS, assessment practices of pain sensation such as modern imaging methods, as well as the barostat method, possess an increased interest to understand mechanisms of visceroperception in IBS. ${ }^{13}$

Dysregulation in the afferent part of the brain-gut axis possesses the potential to induce VH. It has been reported that several novel compounds which possess multiple gastrointestinal pharmacological effects can be considered as future drugs for managing $\mathrm{VH}$ in IBS patients. However, evidence indicating the efficacy, safety and tolerability of the pharmacological agents for managing $\mathrm{VH}$ in patients with IBS are restricted. Gut tissue possesses a wide exposure to external agents such as microbes and nutritional compounds. Several biological cascades are implicated in the physiologic function of the gut including neural, immunological, and mucosal epithelial cell performance. The complex interaction among the neuroimmune pathway, gut-brain axis, as well as intestinal epithelial cells stimulates inflammatory and motility response, resulting in visceroperception and a low threshold of nociception. ${ }^{155}$ The pharmacological research on selective drugs based on targeting specific ligands can result in providing novel effective therapies for modulating persistent visceral hyperalgesia. The current paper has reviewed the cellular and molecular mechanisms underlying therapeutic targeting for providing future drugs in order to protect or treat visceroperception and pain sensitization in IBS patients. Figure illustrates the pharmacological aspects of novel therapeutic targeting for the management of $\mathrm{VH}$ in IBS.

Numerous molecular mediators and receptors participating in pain perception and visceroperception including histamine-1 receptors, 5-HT receptors, transient receptor potential vanilloid type I, tachykinins ligands, opioid receptors, voltage-gated channels, Trk 


\section{Pharmacological targets of future drugs for managing VH in IBS}

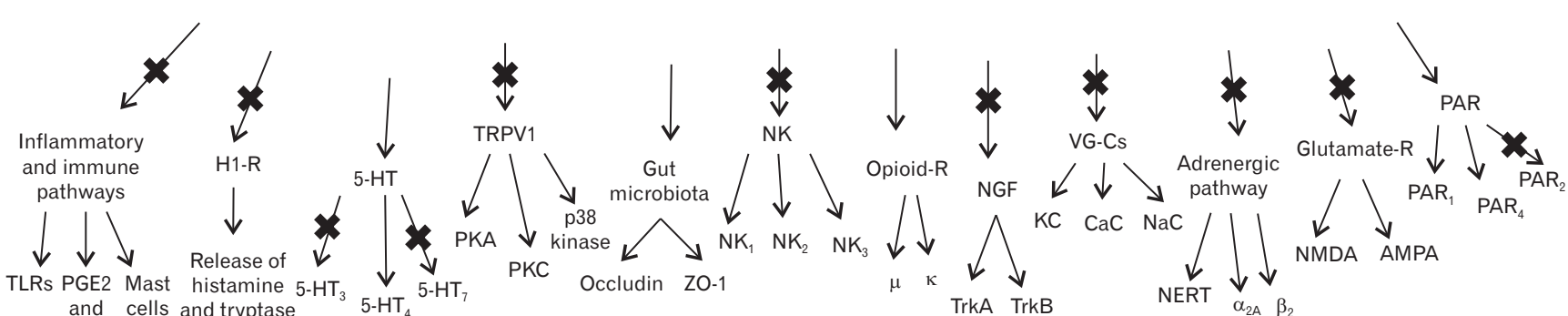
cells and tryptase

IL-1 $\beta$

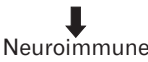

response

Figure. Pharmacological targets of novel drugs for the management of visceral hypersensitivity (VH) in irritable bowel syndrome (IBS). TLRs, Toll-like receptors; PGE2, prostaglandin E2; IL-1 $\beta$, interleukin-1 $\beta$; H1-R, histamine-1 receptor; 5-HT, 5-hydrodytryptamine; TRPV1, transient receptor potential vanilloid type I; PKA, cAMP-dependent protein kinase; PKC, protein kinase C; ZO-1, Zona occludens protein-1; NK, neurokinin; NGF, nerve growth factor; Trk, tyrosine receptor kinase; VG-Cs, voltage-gated channels; KC, potassium channel; CaC, calcium channel; $\mathrm{NaC}$, sodium channel; NERT, norepinephrine reuptake transporter; NMDA, N-methyl-D-aspartate; AMPA, $\alpha$-Amino-3-hydroxy-5-methyl-4isoxazolepropionic acid; PAR, protease-activated receptors; $\mathrm{R}$, receptor.

receptors, protease-activated receptors, adrenergic system ligands, cannabinoid receptors, sex hormones, and glutamate receptors, are considered as specific molecular targets for future treatment of $\mathrm{VH}$. Gut microbiota have also attracted a lot of attention from physicians around the world as a part of treatment in IBS patients. Multispecies probiotic products have shown effectiveness in controlling some abdominal symptoms and improving the quality of life in a number of human studies. In addition, preclinical evaluation exhibited the therapeutic effect of probiotics on gut motility and visceroperception in animal models of IBS. The Table shows a summary of novel drugs and their underlying mechanisms for the management of VH.

Along with the mentioned pharmacological targets with the potential to manage $\mathrm{VH}$, natural compounds could be considered as novel future treatments for $\mathrm{VH}$ in IBS patients. Among the wide range of evaluated molecules, in vitro and animal studies suggest a positive role for curcumin, dicentrine, ginseng saponins, berberine and tetrahydropalmatine in the improvement of visceral pain perception; however, more mechanistic studies as well as clinical trials are necessary to confirm the effectiveness of these novel components. In addition, various CAM approaches, including physiotherapy, traditional medicines, acupuncture, mind-body directed interventions, as well as psychosocial-directed therapies with modest but proven efficacy, are currently employed and are able to help IBS patients in managing $\mathrm{VH}$ and persistent visceral pain.

A wide range of novel pharmacological compounds as well as 
natural molecules is capable of improving visceral complications of IBS; however, the most important limitation on practical use of these products is the lack of enough clinical evidence which requires more studies for better understanding of the mechanisms of action, safety, and efficacy of the above mentioned agents.

In conclusion, it has been confirmed that $\mathrm{VH}$ has an important role in IBS pathology and in the severity of patient complications indicating that managing $\mathrm{VH}$ can remarkably modulate the symptoms of IBS. Preclinical and clinical evaluations of pharmacological targets with the potential to prevent or cure VH in IBS conditions are discussed in the current review in order to provide more efficacious and targeted medicaments rather than conventional treatments

Table. Mechanism of Action and Receptor Targeting of Future Drugs for the Management of Visceral Hypersensitivity

\begin{tabular}{|c|c|c|c|c|}
\hline Source & Agents as future drugs & Cell/ receptor targets & Therapeutic effects in managing $\mathrm{VH}$ & References \\
\hline \multirow[t]{24}{*}{ Chemical } & 5-aminosalicylic acid & Intestinal immune cells & $\downarrow$ Inflammation and pain perception & $19,49,50$ \\
\hline & A- 803467 & $\begin{array}{l}\text { Selective } \mathrm{Na}_{\mathrm{v}} 1.8 \text { sodium } \\
\text { channel blocker }\end{array}$ & $\downarrow$ Mechanical allodynia and thermal hyperalgesia & 90 \\
\hline & Alosetron & $5-\mathrm{HT}_{3}$ receptor antagonist & $\begin{array}{l}\uparrow \text { Volume thresholds, } \\
\downarrow \text { Colonic compliance, } \\
\downarrow \text { Emotional motor system of brain activity and } \\
\text { modulation of the gut sensitivity }\end{array}$ & 60,61 \\
\hline & Ambroxol & $\mathrm{Na}^{+}$channel blocker & $\downarrow$ Inflammatory pain & 91 \\
\hline & Asimadoline & $\kappa$-opioid receptor agonist & $\begin{array}{l}\downarrow \text { Pain sensation, } \\
\downarrow \text { Hyperalgesia in functional dyspepsia }\end{array}$ & $78-80$ \\
\hline & AYPGKF-NH ${ }_{2}$ & PAR4 agonist peptide & $\downarrow V$ isceromotor response to colorectal distension & 102,103 \\
\hline & Capsazepine & TRPV1 receptor antagonist & $\downarrow$ Inflammation and visceral pain & 67,72 \\
\hline & CNQX & $\begin{array}{l}\text { Non-selective glutamate } \\
\text { AMPA receptor antagonist }\end{array}$ & $\downarrow$ Visceral perception induced by substance $\mathrm{P}$ & 96 \\
\hline & Ebastine and fexofenadine & Histamine-1-receptor antagonists & $\downarrow$ Stress associated $\mathrm{VH}$ & 54 \\
\hline & Eluxadoline & $\begin{array}{l}\mu \text {-opioid receptor agonist and } \\
\delta \text {-opioid receptor antagonist }\end{array}$ & $\uparrow$ Pain threshold & 80,81 \\
\hline & Fedotozine & $\kappa$-opioid receptor agonist & $\begin{array}{l}\downarrow \text { Pain sensation, } \\
\downarrow \text { Volume or pressure stimuli perception }\end{array}$ & $78-80$ \\
\hline & $\mathrm{K} 252 \mathrm{~A}$ & TrkA antagonist & $\downarrow \mathrm{VH}$ in colorectal distension & 84 \\
\hline & Ketotifen & $\begin{array}{l}\text { Histamine-1-receptor antagonist } \\
\text { and mast cell stabilizer }\end{array}$ & $\downarrow$ Hyperalgesia, discomfort and abdominal pain & 56 \\
\hline & Lidocaine & $\begin{array}{l}\text { Voltage gated } \mathrm{Na}^{+} \\
\text {channels blocker }\end{array}$ & $\begin{array}{l}\uparrow \text { Pain threshold, } \\
\downarrow \text { Rectal hypersensitivity }\end{array}$ & 89 \\
\hline & $\begin{array}{l}\text { Mibefradil, ethosuximide, } \\
\text { and NP078585 }\end{array}$ & Calcium channel antagonists & $\downarrow$ Butyrate-induced VH & 88 \\
\hline & Nepadutant and saredutant & $\mathrm{NK}_{2}$ receptor antagonists & Modulation the colorectal hypersensitivity to distension & $74-77$ \\
\hline & PF-03550096 & Selective CB2 receptor agonist & $\downarrow$ Visceral hyperalgesia & 101 \\
\hline & Propranolol & $\beta$-adrenergic receptor antagonist & $\downarrow$ Heterotypical intermittent stress-induced $\mathrm{VH}$ & 92,93 \\
\hline & RQ-00202730 & Selective $\mathrm{CB} 2$ receptor agonist & $\downarrow$ Visceral hyperalgesia & 100 \\
\hline & SB366791 & TRPV1 receptor antagonist & $\downarrow$ Thermal hyperalgesia & 71 \\
\hline & $\begin{array}{l}\text { SR-140333 and } \\
\text { MEN-10930 }\end{array}$ & Selective $\mathrm{NK}_{1}$ receptor antagonists & $\downarrow$ Inflammatory associated hyperalgesia & $73-75$ \\
\hline & SR-142801 & Selective $\mathrm{NK}_{3}$ receptor antagonist & $\downarrow$ Inflammatory associated $\mathrm{VH}$ & $75-77$ \\
\hline & TAK-242 & Specific $\mathrm{TLR}_{4}$ receptor antagonist & $\downarrow$ Chronic stress-induced VH & 53 \\
\hline & Tegaserod & Partial 5- $\mathrm{HT}_{4}$ receptor agonist & $\begin{array}{l}\downarrow \text { Sensitivity to rectal distension, } \\
\text { Improved visceral sensation }\end{array}$ & $62-64$ \\
\hline
\end{tabular}


Table. Continued

\begin{tabular}{|c|c|c|c|c|}
\hline Source & Agents as future drugs & Cell/ receptor targets & Therapeutic effects in managing $\mathrm{VH}$ & References \\
\hline \multirow[t]{6}{*}{ Natural } & Berberine & $\begin{array}{l}\text { Involvement of nitric oxide } \\
\text { synthetase }\end{array}$ & $\begin{array}{l}\downarrow \text { Abdominal withdrawal reflex score to colorectal } \\
\text { distention, } \\
\downarrow \text { Defecation times, } \\
\text { Improvement of stool consistency }\end{array}$ & 138 \\
\hline & Curcumin & $\begin{array}{l}\text { Involvement of TRPV } 1 \text { and } \\
\text { 5- } \mathrm{HT}_{1 \mathrm{a}} \text { receptors, Modulation of } \\
\text { BDNF, 5-HT and pCREB }\end{array}$ & $\begin{array}{l}\downarrow \text { Visceromotor response to colorectal distension, } \\
\text { Modulation of depressive behavior in IBS }\end{array}$ & 125,126 \\
\hline & Dicentrine & $\begin{array}{l}\alpha \text {-adrenoceptor antagonist, } \\
\text { Involvement of TRPA } 1 \text { receptors }\end{array}$ & $\downarrow$ Visceral pain perception & 130,131 \\
\hline & Ginseng saponins & $5-\mathrm{HT}_{3 \mathrm{a}}$ receptor blocker & Antinociceptive effect in VH & 141 \\
\hline & Probiotics & Gut microflora & $\begin{array}{l}\downarrow \text { Intestinal permeability and contractile response of } \\
\text { colonic smooth muscle, } \\
\downarrow \text { VH symptoms of post-infectious IBS, } \\
\text { Regulation of pain transmission mediators and } \\
\text { inflammatory cytokines }\end{array}$ & $41,113-115$ \\
\hline & Tetrahydropalmatine & Not identified & $\begin{array}{l}\uparrow \text { Pain threshold, } \\
\downarrow \text { Primary hyperalgesia due to thermal and } \\
\text { mechanical stimuli, Antinociceptive effect }\end{array}$ & 143,145 \\
\hline
\end{tabular}

VH, visceral hypersensitivity; 5-HT, serotonin; PAR, protease-activated receptor; TRPV1, transient receptor potential vanilloid type I; CNQX, 6-cyano-7-nitroquinoxaline-2,3-dione disodium; AMPA, $\alpha$-Amino-3-hydroxy-5-methyl-4-isoxazolepropionic acid; TrkA, tyrosine receptor kinase A; NK, neurokinin; CB, cannabinoid; TLR, toll like receptor; BDNF, brain derived neurotrophic factor; pCREB, phosphorylated cAMP-response element binding protein; IBS, irritable bowel syndrome; TRPA, transient receptor potential cation channel.

for hypersensitive IBS patients. Further well-designed controlled clinical trials are mandatory in order to confirm the therapeutic efficacy and safety of novel pharmacological compounds on $\mathrm{VH}$ in IBS patients.

Acknowledgements: Authors wish to thank the Iran National Science Foundation and The National Elite Foundation for the support of the first author postdoctoral program.

Financial support: This study was in part supported by a grant from Tehran University of Medical Sciences (No. 93-03-8627155).

Conflicts of interest: No competing interests declared.

Author contributions: Mohammad Abdollahi and Roja Rahimi designed the study and edited the manuscript; and Mohammad H Farzaei and Roodabeh Bahramsoltani collected the data and wrote the manuscript.

\section{References}

1. Canavan C, West J, Card T. Review article: the economic impact of the irritable bowel syndrome. Aliment Pharmacol Ther 2014;40:10231034 .

2. Lovell RM, Ford AC. Global prevalence of and risk factors for irritable bowel syndrome: a meta-analysis. Clin Gastroenterol Hepatol 2012;10: 712-721.

3. Nikfar S, Rahimi R, Rahimi F, Derakhshani S, Abdollahi M. Efficacy of probiotics in irritable bowel syndrome: a meta-analysis of randomized, controlled trials. Dis Colon Rectum 2008;51:1775-1780.

4. Akbar A, Walters JR, Ghosh S. Review article: visceral hypersensitivity in irritable bowel syndrome: molecular mechanisms and therapeutic agents. Aliment Pharmacol Ther 2009; 30:423-435.

5. World Gastroenterology Organization. Irritable bowel syndrome: a global perspective. World Gastroenterology Organisation Global Guideline 2009. Available from URL: http:/www.jupiterpharma.in/ journalpdf/IBS WORLD GASTRO.pdf (accessed 22 Sep 2016)

6. Siah KT, Wong RK, Chan YH, Ho KY, Gwee KA. Prevalence of irritable bowel syndrome in Singapore and its association with dietary, lifestyle, and environmental factors. J Neurogastroenterol Motil 2016;22:670676.

7. Lovell RM, Ford AC. Effect of gender on prevalence of irritable bowel syndrome in the community: systematic review and meta-analysis. Am J 
Gastroenterol 2012;107:991-1000.

8. Longstreth GF, Thompson WG, Chey WD, Houghton LA, Mearin F, Spiller RC. Functional bowel disorders. Gastroenterology 2006;130:1480-1491.

9. Sandler RS, Everhart JE, Donowitz M, et al. The burden of selected digestive diseases in the United States. Gastroenterology 2002;122:15001511.

10. Rahimi R, Abdollahi M. Herbal medicines for the management of irritable bowel syndrome: a comprehensive review. World J Gastroenterol 2012;18:589-600.

11. Quigley EM, Bytzer P, Jones R, Mearin F. Irritable bowel syndrome: the burden and unmet needs in Europe. Dig Liver Dis 2006;38:717723.

12. Spiller R, Garsed K. Infection, inflammation, and the irritable bowel syndrome. Dig Liver Dis 2009;41:844-849.

13. Ludidi S, Mujagic Z, Jonkers D, et al. Markers for visceral hypersensitivity in patients with irritable bowel syndrome. Neurogastroenterol Motil 2014;26:1104-1111.

14. Barbara G, De Giorgio R, Stanghellini V, Cremon C, Salvioli B, Corinaldesi R. New pathophysiological mechanisms in irritable bowel syndrome. Aliment Pharmacol Ther 2004;20(suppl 2):1-9.

15. Lee YJ, Park KS. Irritable bowel syndrome: emerging paradigm in pathophysiology. World J Gastroenterol 2014;20:2456-2469.

16. Lackner JM, Gudleski GD, Thakur ER, Stewart TJ, Iacobucci GJ, Spiegel BM. The impact of physical complaints, social environment, and psychological functioning on IBS patients' health perceptions: looking beyond GI symptom severity. Am J Gastroenterol 2014;109:224-233.

17. Saha L. Irritable bowel syndrome: pathogenesis, diagnosis, treatment, and evidence-based medicine. World J Gastroenterol 2014;20:67596773.

18. Lea R, Whorwell PJ. The role of food intolerance in irritable bowel syndrome. Gastroenterol Clin North Am 2005;34:247-255.

19. Leighton MP, Lam C, Mehta S, Spiller RC. Efficacy and mode of action of mesalazine in the treatment of diarrhoea-predominant irritable bowel syndrome (IBS-D): study protocol for a randomised controlled trial. Trials 2013;14:10.

20. American College of Gastroenterology Chronic Constipation Task Force. An evidence-based approach to the management of chronic constipation in North America. Am J Gastroenterol 2005;100(suppl 1): S1S4.

21. Akehurst R, Kaltenthaler E. Treatment of irritable bowel syndrome: a review of randomised controlled trials. Gut 2001;48:272-282.

22. Rahimi R, Nikfar S, Rezaie A, Abdollahi M. Efficacy of tricyclic antidepressants in irritable bowel syndrome: a meta-analysis. World J Gastroenterol 2009;15:1548-1553.

23. Rahimi R, Nikfar S, Abdollahi M. Selective serotonin reuptake inhibitors for the management of irritable bowel syndrome: a meta-analysis of randomized controlled trials. Arch Med Sci 2008;4:71-76.

24. Camilleri M. Testing the sensitivity hypothesis in practice: tools and methods, assumptions and pitfalls. Gut 2002;51:(suppl 1):i34-i40.

25. Eijkelkamp N, Heijnen CJ, Carbajal AG, et al. G protein-coupled receptor kinase 6 acts as a critical regulator of cytokine-induced hyper- algesia by promoting phosphatidylinositol 3-kinase and inhibiting p38 signaling. Mol Med 2012;18:556-564.

26. Bouin M, Meunier P, Riberdy-Poitras M, Poitras P. Pain hypersensitivity in patients with functional gastrointestinal disorders: a gastrointestinal-specific defect or a general systemic condition? Dig Dis Sci 2001;46:2542-2548.

27. Van der veek PP, Van Rood YR, Masclee AA. Symptom severity but not psychopathology predicts visceral hypersensitivity in irritable bowel syndrome. Clin Gastroenterol Hepatol 2008;6:321-328.

28. Kanazawa M, Palsson OS, Thiwan SI, et al. Contributions of pain sensitivity and colonic motility to IBS symptom severity and predominant bowel habits. Am J Gastroenterol 2008;103:2550-2561.

29. Gwee KA, Lu CL, Ghoshal UC. Epidemiology of irritable bowel syndrome in Asia: something old, something new, something borrowed. J Gastroenterol Hepatol 2009;24:1601-1607.

30. Maxion-Bergemann S, Thielecke F, Abel F, Bergemann R. Costs of irritable bowel syndrome in the UK and US. Pharmacoeconomics 2006;24:21-37.

31. Posserud I, Syrous A, Lindström L, Tack J, Abrahamsson H, Simrén M. Altered rectal perception in irritable bowel syndrome is associated with symptom severity. Gastroenterology 2007;133:1113-1123.

32. Zighelboim J, Talley NJ, Phillips SF, Harmsen WS, Zinsmeister AR. Visceral perception in irritable bowel syndrome. Rectal and gastric responses to distension and serotonin type 3 antagonism. Dig Dis Sci 1995;40:819-827.

33. Ludidi S, Conchillo JM, Keszthelyi D, et al. Rectal hypersensitivity as hallmark for irritable bowel syndrome: defining the optimal cutoff. Neurogastroenterol Motil 2012;24:729-733.

34. Ritchie J. Pain from distension of the pelvic colon by inflating a balloon in the irritable colon syndrome. Gut 1973;4:125-132.

35. Lee H, Park JH, Park DI, et al. Mucosal mast cell count is associated with intestinal permeability in patients with diarrhea predominant irritable bowel syndrome. J Neurogastroenterol Motil 2013;19:244-250.

36. Matricon J, Meleine M, Gelot A, et al. Review article: associations between immune activation, intestinal permeability and the irritable bowel syndrome. Aliment Pharmacol Ther. 2012;36:1009-1031.

37. Spiller R, Lam C. An update on post-infectious irritable bowel syndrome: role of genetics, immune activation, serotonin and altered microbiome. J Neurogastroenterol Motil 2012;18:258-268.

38. Thijssen AY, Jonkers DM, Leue C, et al. Dysfunctional cognitions, anxiety and depression in irritable bowel syndrome. J Clin Gastroenterol 2010;44:e236-e241.

39. Barbara G, Cremon C, De Giorgio R, et al. Mechanisms underlying visceral hypersensitivity in irritable bowel syndrome. Curr Gastroenterol Rep 2011;13:308-315.

40. Distrutti E, Cipriani S, Mencarelli A, Renga B, Fiorucci S. Probiotics VSL\#3 protect against development of visceral pain in murine model of irritable bowel syndrome. PLoS One 2013;8:e63893.

41. Wang $\mathrm{H}$, Gong J, Wang W, et al. Are there any different effects of Bifidobacterium, lactobacillus and Streptococcus on intestinal sensation, barrier function and intestinal immunity in pi-ibs mouse model? PLoS One 2014;9:e90153. 
42. Cremon C, Carini G, Wang B, et al. Intestinal serotonin release, sensory neuron activation, and abdominal pain in irritable bowel syndrome. Am J Gastroenterol 2011;106:1290-1298.

43. Kapeller J, Houghton LA, Mönnikes H, et al. First evidence for an association of a functional variant in the microRNA-510 target site of the serotonin receptor-type $3 \mathrm{E}$ gene with diarrhea predominant irritable bowel syndrome. Hum Mol Genet 2008;17:2967-2977.

44. Keszthelyi D, Troost FJ, Simrén M, et al. Revisiting concepts of visceral nociception in irritable bowel syndrome. Eur J Pain 2012;16:1444-1454 .

45. Anand P, Aziz Q, Willert R, van Oudenhove L. Peripheral and central mechanisms of visceral sensitization in man. Neurogastroenterol Motil 2007;19:29-46.

46. Song DD, Li Y, Tang D, Huang LY, Yuan YZ. Neuron-glial communication mediated by $\mathrm{TNF}-\alpha$ and glial activation in dorsal root ganglia in visceral inflammatory hypersensitivity. Am J Physiol Gastrointest Liver Physiol 2014;306:G788-G795.

47. Barbara G, Wang B, Stanghellini V, et al. Mast cell-dependent excitation of visceral-nociceptive sensory neurons in irritable bowel syndrome. Gastroenterology 2007;132:26-37.

48. Gwee KA, Collins SM, Read NW, et al. Increased rectal mucosal expression of interleukin 1beta in recently acquired post-infectious irritable bowel syndrome. Gut 2003;52: 523-526.

49. Corinaldesi R, Stanghellini V, Cremon C, et al. Effect of mesalazine on mucosal immune biomarkers in irritable bowel syndrome: a randomized controlled proof-of-concept study. Aliment Pharmacol Ther 2009;30:245-252.

50. Dorofeyev AE, Kiriyan EA, Vasilenko IV, Rassokhina OA, Elin AF. Clinical, endoscopical and morphological efficacy of mesalazine in patients with irritable bowel syndrome. Clin Exp Gastroenterol 2011; 4:141-153.

51. Villani AC, Lemire M, Thabane M, et al. Genetic risk factors for postinfectious irritable bowel syndrome following a waterborne outbreak of gastroenteritis. Gastroenterology 2010;138:1502-1513.

52. McKernan DP, Gaszner G, Quigley EM, Cryan JF, Dinan TG. Altered peripheral Toll-like receptor responses in the irritable bowel syndrome. Aliment Pharmacol Ther 2011;33:1045-52.

53. Tramullas M, Finger BC, Moloney RD, et al. Toll-like receptor 4 regulates chronic stress-induced visceral pain in mice. Biol psychiatry 2014;76:340-348

54. Stanisor OI, van Diest SA, Yu Z, et al. Stress-induced visceral hypersensitivity in maternally separated rats can be reversed by peripherally restricted histamine-1-receptor antagonists. PLoS One 2013;8:e66884.

55. Coelho AM, Fioramonti J, Bueno L. Mast cell degranulation induces delayed rectal allodynia in rats: role of histamine and 5-HT. Dig Dis Sci 1998:43:727-737.

56. Klooker TK, Braak B, Koopman KE, et al. The mast cell stabiliser ketotifen decreases visceral hypersensitivity and improves intestinal symptoms in patients with irritable bowel syndrome. Gut 2010;59:1213-1221.

57. Stasi C, Bellini M, Bassotti G, Blandizzi C, Milani S. Serotonin receptors and their role in the pathophysiology and therapy of irritable bowel syndrome. Tech Coloproctol 2014;18:613-621.

58. Gershon MD. Plasticity in serotonin control mechanisms in the gut.
Curr Opin Pharmacol 2003;3:600-607.

59. Dunlop SP, Coleman NS, Blackshaw E, et al. Abnormalities of 5-hydroxytryptamine metabolism in irritable bowel syndrome. Clin Gastroenterol Hepatol 2005;3:349-357.

60. Delvaux M, Louvel D, Mamet JP, Campos-Oriola R, Frexinos J. Effect of alosetron on responses to colonic distension in patients with irritable bowel syndrome. Aliment Pharmacol Ther 1998;12:849-855.

61. Mayer EA, Berman S, Derbyshire SW, et al. The effect of the $5-\mathrm{HT}_{3}$ receptor antagonist, alosetron, on brain responses to visceral stimulation in irritable bowel syndrome patients. Aliment Pharmacol Ther 2002;16:1357-1366.

62. Hoffman JM, Tyler K, MacEachern SJ, et al. Activation of colonic mucosal $5-\mathrm{HT}_{4}$ receptors accelerates propulsive motility and inhibits visceral hypersensitivity. Gastroenterology 2012;142:844-654.

63. Coffin B, Farmachidi JP, Rueegg P, Bastie A, Bouhassira D. Tegaserod, a $5-\mathrm{HT}_{4}$ receptor partial agonist, decreases sensitivity to rectal distension in healthy subjects. Aliment Pharmacol Ther 2003;17:577-585.

64. Tack J, Janssen P, Bisschops R, Vos R, Phillips T, Tougas G. Influence of tegaserod on proximal gastric tone and on the perception of gastric distention in functional dyspepsia. Neurogastroenterol Motil 2011, 23:e32-e39.

65. Meuser T, Pietruck C, Gabriel A, Xie GX, Lim KJ, Pierce PP. 5-HT, receptors are involved in mediating 5-HT-induced activation of rat primary afferent neurones. Life Sci 2002;71:2279-2289.

66. Mezey E, Tóth ZE, Cortright DN, et al. Distribution of mRNA for vanilloid receptor subtype 1 (VR1), and VR1-like immunoreactivity, in the central nervous system of the rat and human. Proc Natl Acad Sci USA 2000;97:3655-3660.

67. Akbar A, Yiangou Y, Facer P, Walters JR, Anand P, Ghosh S. Increased capsaicin receptor TRPV1-expressing sensory fibres in irritable bowel syndrome and their correlation with abdominal pain. Gut 2008;57:923929.

68. Premkumar LS, Ahern GP. Induction of vanilloid receptor channel activity by protein kinase C. Nature 2000;408:985-990.

69. Chan CL, Facer P, Davis JB, et al. Sensory fibres expressing capsaicin receptor TRPV1 in patients with rectal hypersensitivity and fecal urgency. Lancet 2003;361:385-391.

70. Winston J, Shenoy M, Medley D, Naniwadekar A, Pasricha PJ. The vanilloid receptor initiates and maintains colonic hypersensitivity induced by neonatal colon irritation in rats. Gastroenterology 2007;132:615-627.

71. Spicarova D, Adamek P, Kalynovska N, Mrozkova P, Palecek J TRPV1 receptor inhibition decreases CCL2-induced hyperalgesia. Neuropharmacology 2014;81:75-84.

72. Kimball ES, Wallace NH, Schneider CR, D'Andrea MR, Hornby PJ. Vanilloid receptor 1 antagonists attenuate disease severity in dextran sulphate sodium-induced colitis in mice. Neurogastroenterol Motil 2004;16:811-818.

73. Bradesi S, Kokkotou E, Simeonidis S, et al. The role of neurokinin 1 receptors in the maintenance of visceral hyperalgesia induced by repeated stress in rats. Gastroenterology 2006;130:1729-1742.

74. Bueno L, Fioramonti J, Garcia-Villar R. Pathobiology of visceral pain: molecular mechanisms and therapeutic implications. III. Visceral affer- 
ent pathways: a source of new therapeutic targets for abdominal pain. Am J Physiol Gastrointest Liver Physiol 2000;278:G670-G676.

75. Julia V, Su X, Buéno L, Gebhart GF. Role of neurokinin 3 receptors on responses to colorectal distention in the rat: electrophysiological and behavioral studies. Gastroenterology 1999;116:1124-1131.

76. Houghton LA, Cremonini F, Camilleri M, et al. Effect of the $\mathrm{NK}_{3}$ receptor antagonist, talnetant, on rectal sensory function and compliance in healthy humans. Neurogastroenterol Motil 2007;19:732-743.

77. Gaudreau GA, Plourde V. Role of tachykinin $\mathrm{NK}_{1}, \mathrm{NK}_{2}$ and $\mathrm{NK}_{3}$ receptors in the modulation of visceral hypersensitivity in the rat. Neurosci Lett 2003;351:59-62.

78. Delvaux M, Beck A, Jacob J, Bouzamondo H, Weber FT, Frexinos J. Effect of asimadoline, a kappa opioid agonist, on pain induced by colonic distension in patients with irritable bowel syndrome. Aliment Pharmacol Ther 2004;20:237-246.

79. Delvaux M, Louvel D, Lagier E, Scherrer B, Abitbol JL, Frexinos J. The kappa agonist fedotozine relieves hypersensitivity to colonic distention in patients with irritable bowel syndrome. Gastroenterology 1999;116:38-45.

80. Mangel AW, Bornstein JD, Hamm LR, et al. Clinical trial: asimadoline in the treatment of patients with irritable bowel syndrome. Aliment Pharmacol Ther 2008;28:239-249.

81. Dove LS, Lembo A, Randall CW, et al. Eluxadoline benefits patients with irritable bowel syndrome with diarrhea in a phase 2 study. Gastroenterology 2013;145:329-338.

82. Coulie B, Szarka LA, Camilleri M, et al. Recombinant human neurotrophic factors accelerate colonic transit and relieve constipation in humans. Gastroenterology 2000;119:41-50.

83. di Mola FF, Friess H, Zhu ZW, et al. Nerve growth factor and Trk high affinity receptor (TrkA) gene expression in inflammatory bowel disease. Gut 2000;46:670-679.

84. Lecht S, Arien-Zakay H, Kohan M, Lelkes PI, Lazarovici P. Angiostatic effects of $\mathrm{K} 252 \mathrm{a}$, a Trk inhibitor, in murine brain capillary endothelial cells. Mol Cell Biochem 2010;339:201-213.

85. Qiao LY, Grider JR. Colitis elicits differential changes in the expression levels of receptor tyrosine kinase $\operatorname{Trk} A$ and $\operatorname{TrkB}$ in colonic afferent neurons: a possible involvement of axonal transport. Pain 2010;151:117127.

86. Stewart T, Beyak MJ, Vanner $\mathrm{S}$. Ileitis modulates potassium and sodium currents in guinea pig dorsal root ganglia sensory neurons. J Physiol 2003;552:797-807.

87. Kirschstein T, Rehberg M, Bajorat R, Tokay T, Porath K, Köhling R. High $\mathrm{K}^{+}$-induced contraction requires depolarization-induced $\mathrm{Ca}^{2+}$ release from internal stores in rat gut smooth muscle. Acta Pharmacol Sin 2009;30:1123-1131.

88. Marger F, Gelot A, Alloui A, et al. T-type calcium channels contribute to colonic hypersensitivity in a rat model of irritable bowel syndrome. Proc Natl Acad Sci USA 2011;108:11268-11273.

89. Verne GN, Sen A, Price DD. Intrarectal lidocaine is an effective treatment for abdominal pain associated with diarrhea predominant irritable bowel syndrome. J Pain 2005;6:493-496.

90. Jarvis MF, Honore P, Shieh CC, et al. A-803467, a potent and selective
$\mathrm{Na}_{\mathrm{v}} 1.8$ sodium channel blocker, attenuates neuropathic and inflammatory pain in the rat. Proc Natl Acad Sci USA 2007;104:8520-8525.

91. Gaida W, Klinder K, Arndt K, Weiser T. Ambroxol, a Nav1.8-preferring $\mathrm{Na}^{+}$channel blocker, effectively suppresses pain symptoms in animal models of chronic, neuropathic and inflammatory pain. Neuropharmacology 2005;49:1220-1227.

92. Zhang C, Rui YY, Zhou YY, et al. Adrenergic $\beta 2$-receptors mediates visceral hypersensitivity induced by heterotypic intermittent stress in rats. PLoS One 2014;9:e94726.

93. Winston JH, Xu GY, Sarna SK. Adrenergic stimulation mediates visceral hypersensitivity to colorectal distension following heterotypic chronic stress. Gastroenterology 2010;138:294-304, e3.

94. Zhou L, Huang J, Gao J, Zhang G, Jiang J. NMDA and AMPA receptors in the anterior cingulate cortex mediates visceral pain in visceral hypersensitivity rats. Cell Immunol 2014;287:86-90.

95. Wu X, Gao J, Yan J, Fan J, Owyang C, Li Y. Role for NMDA receptors in visceral nociceptive transmission in the anterior cingulate cortex of viscerally hypersensitive rats. Am J Physiol Gastrointest Liver Physiol 2008;294:G918-G927.

96. Nakayama T, Naono R, Ikeda T, Nishimori T. NMDA and AMPA receptors contribute to the maintenance of substance $\mathrm{P}$-induced thermal hyperalgesia. Neurosci Res 2010;67:18-24.

97. Coutinho SV, Plotsky PM, Sablad M, et al. Neonatal maternal separation alters stressinduced responses to viscerosomatic nociceptive stimuli in rat. Am J Physiol Gastrointest Liver Physiol 2002;282:G307-G316.

98. Ji Y, Tang B, Traub RJ. Modulatory effects of estrogen and progesterone on colorectal hyperalgesia in the rat. Pain 2005;117:433-442.

99. Lu CL, Hsieh JC, Tsaur ML, et al. Estrogen rapidly modulates mustard oil-induced visceral hypersensitivity in conscious female rats: a role of CREB phosphorylation in spinal dorsal horn neurons. Am J Physiol Gastrointest Liver Physiol 2007;292:G438-G446.

100. Iwata Y, Ando K, Taniguchi K, Koba N, Sugiura A, Sudo M. Identification of a highly potent and selective CB2 agonist, RQ-00202730, for the treatment of irritable bowel syndrome. Bioorg Med Chem Lett 2015;25:236-240.

101. Kikuchi A, Ohashi K, Sugie Y, Sugimoto H, Omura H. Pharmacological evaluation of a novel cannabinoid $2\left(\mathrm{CB}_{2}\right)$ ligand, PF-03550096, in vitro and in vivo by using a rat model of visceral hypersensitivity. J Pharmacol Sci 2008;106:219-224.

102. Augé C, Balz-Hara D, Steinhoff M, Vergnolle N, Cenac N. Proteaseactivated receptor-4 $\left(\mathrm{PAR}_{4}\right)$ : a role as inhibitor of visceral pain and hypersensitivity. Neurogastroenterol Motil 2009;21:1189-e107.

103. Tillu DV, Hassler SN, Burgos-Vega CC, et al. Protease activated receptor $2\left(\mathrm{PAR}_{2}\right)$ activation is sufficient to induce the transition to a chronic pain state. Pain 2015;156:859-867.

104. Vergnolle, N. Review article: proteinase-activated receptors-novel signals for gastrointestinal pathophysiology. Aliment Pharmacol Ther 2000;14:257-266.

105. Cenac N. Protease-activated receptors as therapeutic targets in visceral pain. Curr Neuropharmacol 2013;11:598-605.

106. Guarner F, Malagelada JR. Gut flora in health and disease. Lancet 2003;361:512-519. 
107. Penders J, Thijs C, Vink C, et al. Factors influencing the composition of the intestinal microbiota in early infancy. Pediatrics 2006;118:511-521.

108. Macpherson AJ, Geuking MB, McCoy KD. Immune responses that adapt the intestinal mucosa to commensal intestinal bacteria. Immunology 2005;115:153-162.

109. Rijkers GT, De Vos WM, Brummer RJ, Morelli L, Corthier G, Marteau $\mathrm{P}$. Health benefits and health claims of probiotics: bridging science and marketing. Br J Nutr 2011;106:1291-1296.

110. O’Mahony L, McCarthy J, Kelly P, et al. Lactobacillus and Bifidobacterium in irritable bowel syndrome: symptom responses and relationship to cytokine profiles. Gastroenterology 2005;128:541-551.

111. Kurugöl Z, Koturoğlu G. Effects of Saccharomyces boulardii in children with acute diarrhoea. Acta Paediatr 2005;94:44-47.

112. Hun L . Bacillus coagulans significantly improved abdominal pain and bloating in patients with ibs. Postgrad Med 2009;121:119-124.

113. Nébot-Vivinus M, Harkat C, Bzioueche $\mathrm{H}$, et al. Multispecies probiotic protects gut barrier function in experimental models. World J Gastroenterol 2014;20:6832-6843.

114. Distrutti E, Cipriani S, Mencarelli A, Renga B, Fiorucci S. Probiotics VSL\# 3 protect against development of visceral pain in murine model of irritable bowel syndrome. PLoS One 2013;8:e63893.

115. Sisson G, Ayis S, Sherwood RA, Bjarnason I. Randomised clinical trial: a liquid multi-strain probiotic vs. placebo in the irritable bowel syndrome - a 12 week double-blind study. Aliment Pharmacol Ther 2014;40:5162.

116. Roberts LM, McCahon D, Holder R, Wilson S, Hobbs FD. A randomised controlled trial of a probiotic 'functional food' in the management of irritable bowel syndrome. BMC Gastroenterol 2013;13:45.

117. Moayyedi P, Ford AC, Talley NJ, et al. The efficacy of probiotics in the treatment of irritable bowel syndrome: a systematic review. Gut 2010;59:325-332.

118. Aggarwal BB, Sundaram C, Malani N, Ichikawa H. Curcumin: the Indian solid gold. Adv Exp Med Biol 2007;595:1-75.

119. Farzaei MH, Abdollahi M, Rahimi R. Role of dietary polyphenols in the management of peptic ulcer. World J Gastroenterol 2015;21:64996517.

120. Mun SH, Kim SB, Kong R, et al. Curcumin reverse methicillin resistance in Staphylococcus aureus. Molecules 2014;19:18283-18295.

121. Bahramsoltani R, Farzaei MH, Farahani MS, Rahimi R. Phytochemical constituents as future antidepressants: a comprehensive review. Rev Neurosci 2015;26:699-719.

122. Farzaei MH, Rahimi R, Abdollahi M. The role of dietary polyphenols in the management of inflammatory bowel disease. Curr Pharm Biotechnol 2015;16:196-210.

123. Sharma S, Kulkarni SK, Agrewala JN, Chopra K. Curcumin attenuates thermal hyperalgesia in a diabetic mouse model of neuropathic pain. Eur J Pharmacol 2006;536:256-261.

124. Bundy R, Walker AF, Middleton RW, Booth J. Turmeric extract may improve irritable bowel syndrome symptomology in otherwise healthy adults: a pilot study. J Altern Complement Med 2004;10:1015-1018.

125. Yu Y, Wu S, Li J, et al. The effect of curcumin on the brain-gut axis in rat model of irritable bowel syndrome: involvement of 5-HT-dependent signaling. Metab Brain Dis 2015;30:47-55.

126. Zhi L, Dong L, Kong D, et al. Curcumin acts via transient receptor potential vanilloid-1 receptors to inhibit gut nociception and reverses visceral hyperalgesia. Neurogastroenterol Motil 2013;25:e429-e440.

127. Szallasi A, Cortright DN, Blum CA, Eid SR. The vanilloid receptor TRPV1: 10 years from channel cloning to antagonist proof-of-concept. Nat Rev Drug Discov 2007;6:357-372.

128. Su MJ, Nieh YC, Huang HW, Chen CC. Dicentrine, an alphaadrenoceptor antagonist with sodium and potassium channel blocking activities. Naunyn Schmiedebergs Arch Pharmacol 1994;349:42-49.

129. Yu SM, Chen CC, Ko FN, Huang YL, Huang TF, Teng CM. Dicentrine, a novel antiplatelet agent inhibiting thromboxane formation and increasing the cyclic AMP level of rabbit platelets. Biochem Pharmacol 1992;43:323-329.

130. Montrucchio DP, Córdova MM, Santos AR. Plant derived aporphinic alkaloid s-(+)-dicentrine induces antinociceptive effect in both acute and chronic inflammatory pain models: evidence for a role of trpa1 channels. PLoS One 2013;8:e67730.

131. Montrucchio DP, Miguel OG, Zanin SMW, da Silva GA, Cardozo AM, Santos AR. Antinociceptive effects of a chloroform extract and the alkaloid dicentrine isolated from fruits of Ocotea puberula. Planta Med 2012;78:1543-1548.

132. Cromwell BT. Experiments on the origin and function of berberine in Berberis Darwinii. Biochem J 1933;27:860-872.

133. Gulfraz M, Mehmood S, Ahmad A, Fatima N, Praveen Z, Williamson EM. Comparison of the antidiabetic activity of Berberis lyceum root extract and berberine in alloxan-induced diabetic rats. Phytother Res 2008;22:1208-1212.

134. Kuo CL, Chi CW, Liu TY. The anti-inflammatory potential of berberine in vitro and in vivo. Cancer Lett 2004;203:127-137.

135. Shirwaikar A, Shirwaikar A, Rajendran K, Punitha IS. In vitro antioxidant studies on the benzyl tetra isoquinoline alkaloid berberine. Biol Pharm Bull 2006;29:1906-1910.

136. Pan LR, Tang Q, Fu Q, Hu BR, Xiang JZ, Qian JQ. Roles of nitric oxide in protective effect of berberine in ethanol-induced gastric ulcer mice. Acta Pharmacol Sin 2005;26:1334-1338.

137. Deng X, Zhao X, Han J, et al. Synthesis and biological evaluation of berberine derivatives as IBS modulator. Lett Drug Des Discov 2012;9:489-493.

138. Tang QL, Lai ML, Zhong YF, Wang AM, Su JK, Zhang MQ. Antinociceptive effect of berberine on visceral hypersensitivity in rats. World J Gastroenterol 2013;19:4582-4589.

139. Gong Z, Chen Y, Zhang R, et al. Pharmacokinetic comparison of berberine in rat plasma after oral administration of berberine hydrochloride in normal and post inflammation irritable bowel syndrome rats. Int J Mol Sci 2014;15:456-467.

140. Shergis JL, Zhang AL, Zhou W, Xue CC. Panax ginseng in randomised controlled trials: a systematic review. Phytother Res 2013;27: 949-965.

141. Kim JH, Nah SY. Effects of ginsenoside total saponins on experimental irritable bowel syndrome in rats. J Ginseng Res 2005;29:94-99.

142. Kim JH, Lee JH, Jeong SM, et al. Effect of ginseng saponins on a rat 
visceral hypersensitivity model. Biol Pharm Bull 2005;28:2120-2124.

143. Cao FL, Shang GW, Wang Y, Yang F, Li CL, Chen J. Antinociceptive effects of intragastric DL-tetrahydropalmatine on visceral and somatic persistent nociception and pain hypersensitivity in rats. Pharmacol Biochem Behav 2011;100:199-204.

144. Han Y, Zhang W, Tang Y, et al. l-Tetrahydropalmatine, an active component of Corydalis yanhusuo W.T. Wang, protects against myocardial ischaemia-reperfusion injury in rats. PLoS One 2012;7:e38627.

145. Bian ZX, Zhang M, Han QB, Xu HX, Sung JJ. Analgesic effects of JCM-16021 on neonatal maternal separation-induced visceral pain in rats. World J Gastroenterol 2010;16:837-845.

146. Tillisch K. Complementary and alternative medicine for functional gastrointestinal disorders. Gut 2006;55:593-596.

147. Yoon SL, Grundmann O, Koepp L, Farrell L. Management of irritable bowel syndrome (IBS) in adults: conventional and complementary/alternative approaches. Altern Med Rev 2011;16:134-151.

148. Wu JC. Complementary and alternative medicine modalities for the treatment of irritable bowel syndrome: facts or myths? Gastroenterol Hepatol (N Y) 2010;6:705-711.

149. Ma XP, Hong J, An CP, et al. Acupuncture-moxibustion in treating irritable bowel syndrome: how does it work? World J Gastroenterol 2014;20:6044-6054.

150. Shen YH, Nahas R. Complementary and alternative medicine for treatment of irritable bowel syndrome. Can Fam Physician 2009;55:143-148.

151. Xiao WB, Liu YL. Rectal hypersensitivity reduced by acupoint TENS in patients with diarrhea-predominant irritable bowel syndrome: a pilot study. Dig Dis Sci 2004;49:312-319.

152. Xing J, Larive B, Mekhail N, Soffer E. Transcutaneous electrical acustimulation can reduce visceral perception in patients with the irritable bowel syndrome: a pilot study. Altern Ther Health Med 2004;10:3842.

153. Farzaei MH, Bahramsoltani R, Rahimi R, Abbasabadi F, Abdollahi M. A systematic review of plant-derived natural compounds for anxiety disorders. Curr Top Med Chem 2016;16:1924-1942.

154. Greenwood-van Meerveld B. Importance of 5-hydroxytryptamine receptors on intestinal afferents in the regulation of visceral sensitivity. Neurogastroenterol Motil 2007;19(suppl 2):13-18.

155. Sharkey KA, Mawe GM. Neuroimmune and epithelial interactions in intestinal inflammation. Curr Opin Pharmacol 2002;2:669-677. 